\title{
The role of auditory temporal cues in the fluency of stuttering adults
}

\author{
Juliana Furini ${ }^{(1)}$ \\ Luana Altran Picoloto ${ }^{(1)}$ \\ Eduarda Marconato ${ }^{(1)}$ \\ Anelise Junqueira Bohnen (2) \\ Ana Claudia Vieira Cardoso(1) \\ Cristiane Moço Canhetti de Oliveira ${ }^{(1)}$
}

\begin{abstract}
(1) Faculdade de Filosofia e Ciências da Universidade Estadual Paulista, UNESP, Marília, SP, Brazil.

(2) Instituto Brasileiro de Fluência, São Paulo, SP, Brazil.

Study conducted at the Laboratório de Estudos da Fluência - LAEF and at the Laboratório de Investigação do Processamento Auditivo Central - LIPAC

Departamento de Fonoaudiologia, Faculdade de Filosofia e Ciências, Universidade Estadual Paulista "Júlio de Mesquita Filho" - UNESP - Marilia (SP), Brasil.

Research support source: FAPESP
\end{abstract}

Conflict of interest: Nonexistent

Received on: March 28, 2017 Accepted on: August 11, 2017

Mailing address:

Cristiane Moço Canhetti de Oliveira

Av. Hygino Muzzi Filho, 737, Vila

Universitária - Marília, São Paulo, Brasil CEP: $17525-000$

E-mail: cmcoliveira@marilia.unesp.br

\section{ABSTRACT}

Purpose: to compare the frequency of disfluencies and speech rate in spontaneous speech and reading in adults with and without stuttering in non-altered and delayed auditory feedback (NAF, DAF).

Methods: participants were 30 adults: 15 with Stuttering (Research Group - RG), and 15 without stuttering (Control Group - CG). The procedures were: audiological assessment and speech fluency evaluation in two listening conditions, normal and delayed auditory feedback (100 milliseconds delayed by Fono Tools software).

Results: the DAF caused a significant improvement in the fluency of spontaneous speech in RG when compared to speech under NAF. The effect of DAF was different in CG, because it increased the common disfluencies and the total of disfluencies in spontaneous speech and reading, besides showing an increase in the frequency of stuttering-like disfluencies in reading. The intergroup analysis showed significant differences in the two speech tasks for the two listening conditions in the frequency of stuttering-like disfluencies and in the total of disfluencies, and in the flows of syllable and word-per-minute in the NAF.

Conclusion: the results demonstrated that delayed auditory feedback promoted fluency in spontaneous speech of adults who stutter, without interfering in the speech rate. In non-stuttering adults an increase occurred in the number of common disfluencies and total of disfluencies as well as reduction of speech rate in spontaneous speech and reading.

Keywords: Speech; Stuttering; Feedback; Hearing; Evaluation 


\section{INTRODUCTION}

Speech is a high complexity linguistic and motor act, taking into consideration that it requires the harmonic and temporal coordination of neural, muscular (respiratory, phonatory and articulatory) and auditory processes. Fluency is the result of the synchrony between neuronal activities necessary for speech ${ }^{1}$. Therefore, fluency is one of the aspects of speech production, characterized as a multifaceted phenomenon, composed by the following elements: hesitations or disfluencies, reformulations, fluent silent pauses, speech rate or speech velocity, smoothness or ease of emission, grammatical ability and semantic complexity ${ }^{2,3}$. Disfluencies may present with muscular tension and impair the smoothness of speech ${ }^{4}$, and speech rate ${ }^{5}$.

Stuttering has been described as a disorder in the temporal motor sequence of speech ${ }^{6}$, and a fluency disorder that interrupts rhythm and time, producing frequent repetitions, prolongations and blocks of syllables and words ${ }^{7}$. Persistent Developmental Stuttering presents characteristics of chronicity and varying degrees of severity ${ }^{8}$. It is the main and most prevalent fluency disorder, and it is not only related to disfluencies, but also to readiness in motor programming of slowed speech ${ }^{9,10}$ and abnormal motor preparation $^{11}$.

Many studies ${ }^{12-16}$ with neuroimaging performed in persons who stutter have shown relevant results on the auditory regions and their connections with other brain areas in the speech production. The presence of a generalized motor sensorial temporal deficit due to the communication impairment between the brain areas related to the speech of stutters was described ${ }^{12}$. Deficits in auditory and motor integration were reported by several researchers ${ }^{13,14}$. Atypical development of the auditory-motor and thalamic-cortical circuits of the basal ganglia was found in children with stuttering, which in turn, affects the speech planning and execution processes required to achieve motor control of fluent speech $^{15}$. Adults who stutter showed hyperactivity in right hemisphere regions such as the inferior frontal cortex (IFC) and the anterior insula but at the same time, presented fewer activations in the left hemisphere regions like those of the IFC and the left temporal cortex when compared to fluent control groups on various speech tasks and auditory perception ${ }^{16}$.

The interaction between the auditory aspects and the speech fluency has been demonstrated in the literature ${ }^{17-21}$, arousing thus the interest among researchers about the topic of stuttering and hearing.

Studies in fluent individuals have shown that delayed auditory feedback (DAF) has caused difficulties in speech fluency ${ }^{16-22}$, and decrease in speech rate ${ }^{23-25}$.

In persons who stutter the delay in the delayed auditory feedback caused the increase of fluency ${ }^{26-29}$ and the decrease of stuttering ${ }^{30}$. There is no consensus among the researchers about the effect of DAF caused in the speech rate of people with stuttering.

A systematic review of researches related to the effects of altering auditory feedback on speech fluency in stutterers concluded that the exclusive use of delayed auditory feedback does not provide conclusive results $^{31}$. The authors suggest some considerations for the future researches planning as: expansion of the number of participants, existence of the control group, masking of groups, among others.

The purpose of this study was to compare the frequency of disfluencies and the speech rate of spontaneous speech and reading between the non-altered auditory feedback (NAF) and delayed auditory feedback (DAF) in adults with and without stuttering.

\section{METHODS}

This study was approved by the Research Ethics Committee of the Universidade Estadual Paulista "Júlio de Mesquita Filho" (UNESP) under the protocol number 0669/2013. All participants signed the Informed Consent Form before participating in the study. All the recommendations of the Resolution CNS 466/2012 were followed.

This study is a cross-sectional prospective study with comparison between groups. The sample consisted of 30 adults, aged from eighteen to forty-six years (mean $=28.66$ years, $S D=10.04$ ). The research group (RG) consisted of 15 adults with persistent developmental stuttering, being 12 of the masculine gender and 3 of the feminine gender. The control group (CG) was composed of 15 fluent adults, matched by gender and age at RG.

The adults from the research group were originated from the Fluency Studies Laboratory - FSL of the institution of origin.

The inclusion requirements of the two groups were: to be native speaker of Brazilian Portuguese and aged from 18 years to 59 years and 11 months. Adults with stuttering $(R G)$ should present: stuttering complaint; speech-language pathologist diagnosis of persistent developmental stuttering performed by a 
specialist professional in the area; present at least 3\% of stuttering-like disfluencies, observed in the speech for a minimum of 12 months, and; present stuttering classified at least as mild degree according to the Stuttering Severity Instrument - SSI-332.

For the control group composition of fluent adults (CG), the following inclusion criteria were followed: do not present current or previous stuttering complaint; negative stuttering familial history; present less than $3 \%$ of stuttering-like disfluencies in the fluency evaluation.

The exclusion criteria for the two groups were: to present other speech and hearing complaints, auditory, neurological, behavioral, learning disorders, or other pertinent alterations that could generate diagnostic errors.

Regarding the characterization of adults from $R G$, it was possible to verify that the mean age at the beginning of stuttering was 4.13 years. Most of the participants $(86.6 \%)$ had familial persistent developmental stuttering, with a variation in the percentage of stuttering-like disfluencies from 3.0 to $12.5 \%$ (mean $=7.17, \mathrm{SD}=2.72)$ (Table 1$)$. The stuttering severity ranged from mild to severe, with a SSI-3 total average score of 26.33 (from 18 to 35). The adults from CG were matched by gender and age at RG, and the stutteringlike disfluencies percentage ranged from 0 to $1 \%$ (mean $=0.40, \mathrm{SD}=0.47$ ).

\section{Procedures}

Initially the adults received information about the objectives of the study, and explanation about the procedures that were performed and provided written consent for participation in the research. The data collection was performed through audiovisual recording, transcription and analysis of the spontaneous speech fluency and reading in both groups (RC and $C G)$.

The collected speech samples consisted of spontaneous speech (monologue) and reading of a text, in two different listening conditions, namely: non-altered auditory feedback (NAF) and delayed auditory feedback (DAF). The oral reading was carried out through a text suitable for adults ${ }^{33}$.
The audiovisual recordings of a self-expressive speech sample composed of 200 fluent syllables and a text reading were performed using a camera, tripod, earphone and microphone connected to a computer in which software was used (Fono Tools). Adult's speech was recorded and processed using a software that performed Delayed Auditory Feedback (DAF) and it was returned to the adult's ear with a delay of 100 milliseconds through the earphone.

After the adults' speech collection, they were transcribed in full, considering the fluent and not fluent syllables. Subsequently, analyzes of the speech samples were performed and the typology of disfluencies was characterized, according to the following description ${ }^{34}$ :

- Common Disfluencies: hesitations, interjections, revisions, unfinished words, segments repetition, words repetition and phrases repetition.

- Stuttering-Like Disfluencies: two or more repetitions of sounds and/or syllables and/or words, prolongations, blocks, pauses and intrusions.

To characterize the frequency of disruptions, the following measures were used: percentage of speech discontinuity, percentage of common disfluencies and percentage of stuttering-like disfluencies. The speech rate was measured in flow of syllables (SPM) and words per minute (WPM).

The Stuttering Severity Instrument (SSI-3) ${ }^{32}$ was used for each stuttering adult participant classifying stuttering as mild, moderate, severe, or very severe. This test evaluates the frequency and duration of atypical speech disruptions and the presence of physical concomitants associated with disfluencies.

\section{Statistical method}

For the statistical treatment were used: the non-parametric Mann-Whitney test for the group comparison, and the Wilcoxon Signal Test for the intragroup comparison. The values of statistical significance were set at $p<0.05$. Significant $p$-values were highlighted with the asterisk $\left(^{*}\right)$ symbol. 
Table 1. Description of the participants from the research group and the control group

\begin{tabular}{|c|c|c|c|c|c|c|c|}
\hline Adults & Age & Gender & $\begin{array}{l}\text { Familial } \\
\text { history }\end{array}$ & $\begin{array}{l}\text { Onset of } \\
\text { Stuttering }\end{array}$ & $\begin{array}{c}\text { Stuttering- } \\
\text { Like } \\
\text { Disfluencies }\end{array}$ & SSI-3 Score & $\begin{array}{l}\text { Stuttering } \\
\text { severity }\end{array}$ \\
\hline RG 01 & 21 & $M$ & Yes & 4 & 8.5 & 30 & Moderate \\
\hline RG 02 & 27 & $M$ & Yes & 7 & 4.5 & 26 & Mild \\
\hline $\mathrm{RG} 03$ & 47 & M & Yes & 6 & 3.0 & 20 & Mild \\
\hline $\mathrm{RG} 04$ & 23 & $\mathrm{~F}$ & No & 3 & 4.5 & 23 & Mild \\
\hline RG 05 & 21 & M & Yes & 2 & 6.5 & 23 & Mild \\
\hline RG 06 & 42 & $\mathrm{~F}$ & Yes & 4 & 8.0 & 31 & Moderate \\
\hline RG 07 & 18 & $M$ & Yes & 4 & 10.5 & 35 & Severe \\
\hline $\mathrm{RG} 08$ & 19 & $\mathrm{~F}$ & Yes & 3 & 9.0 & 34 & Severe \\
\hline RG 09 & 32 & M & Yes & 8 & 7.0 & 24 & Mild \\
\hline $\mathrm{RG} 10$ & 20 & $M$ & Yes & 3 & 9.0 & 31 & Moderate \\
\hline $\mathrm{RG} 11$ & 24 & M & Yes & 3 & 4.0 & 18 & Mild \\
\hline $\mathrm{RG} 12$ & 18 & M & Yes & 4 & 9.5 & 28 & Moderate \\
\hline$R G 13$ & 36 & M & Yes & 3 & 6.5 & 22 & Mild \\
\hline $\mathrm{RG} 14$ & 46 & M & Yes & 2 & 12.5 & 32 & Severe \\
\hline $\mathrm{RG} 15$ & 37 & $\mathrm{M}$ & No & 6 & 4.5 & 18 & Mild \\
\hline Mean & 28.73 & & & 4.13 & 7.17 & 26.33 & \\
\hline SD & 10.41 & & & 1.80 & 2.72 & 5.67 & \\
\hline CG 01 & 21 & $M$ & No & & 0.5 & & \\
\hline CG 02 & 28 & M & No & & 0 & & \\
\hline CG 03 & 46 & M & No & & 1.0 & & \\
\hline CG 04 & 23 & $\mathrm{~F}$ & No & & 0 & & \\
\hline CG 05 & 21 & M & No & & 0.5 & & \\
\hline CG 06 & 41 & $\mathrm{~F}$ & No & & 1.0 & & \\
\hline CG 07 & 18 & $M$ & No & & 0 & & \\
\hline CG 08 & 19 & $\mathrm{~F}$ & No & & 0 & & \\
\hline CG 09 & 32 & $M$ & No & & 1.0 & & \\
\hline CG 10 & 21 & $M$ & No & & 0 & & \\
\hline CG 11 & 24 & M & No & & 0 & & \\
\hline CG 12 & 18 & $M$ & No & & 1.0 & & \\
\hline CG 13 & 35 & $M$ & No & & 0 & & \\
\hline CG 14 & 46 & $M$ & No & & 1.0 & & \\
\hline CG 15 & 36 & $M$ & No & & 0 & & \\
\hline Mean & 28.06 & & & & 0.40 & & \\
\hline SD & 10.03 & & & & 0.47 & & \\
\hline
\end{tabular}

Subtitle: $\mathrm{RG}=$ research group; $\mathrm{CG}=$ control group; $\mathrm{SD}=$ standard deviation; $\mathrm{M}=$ male; $\mathrm{F}=$ female; $\mathrm{SSI}-3=$ Stuttering Severity Instrument

\section{RESULTS}

Results regarding spontaneous speech are presented in Table 2. The intragroup comparison of adults with stuttering (RG) showed a statistically significant difference between NAF and DAF conditions only for stuttering-like disfluencies. The delay in auditory feedback caused a decrease in the frequency of stuttering-like disfluencies.

Fluent adults (CG) showed statistically significant differences for common disfluencies, speech discontinuity, flows of syllable and word-per-minute between NAF and DAF conditions. There was an increase in the common disfluencies occurrence and speech discontinuity in spontaneous speech with delayed auditory feedback, and a decrease in the flow of syllables and words per minute (Table 2).

The comparison between RG and $C G$ showed that in the NAF condition there were statistically significant differences for stuttering-like disfluencies, speech discontinuity, flows of syllables and words per 
Table 2. Intragroup and intergroup comparisons regarding the occurrence of stuttering-like disfluencies, common disfluencies, speech discontinuity, flow of syllables and words per minute, in the conditions of non-altered and delayed auditory feedback in spontaneous speech

\begin{tabular}{|c|c|c|c|c|c|c|c|c|c|c|}
\hline \multirow{2}{*}{\multicolumn{2}{|c|}{ Variables }} & \multicolumn{4}{|c|}{$R G(N=15)$} & \multicolumn{4}{|c|}{$C G(N=15)$} & \multirow{2}{*}{$P$ value } \\
\hline & & Mean & SD & Minimum & Maximum & Mean & SD & Minimum & Maximum & \\
\hline Stuttering-Like & NAF & 7.17 & 2.72 & 3.00 & 12.50 & 0.40 & 0.47 & 0.00 & 1.00 & $<0.001^{*}$ \\
\hline Disfluencies & DAF & 5.20 & 3.61 & 1.50 & 12.00 & 0.53 & 0.77 & 0.00 & 2.00 & $<0.001^{*}$ \\
\hline$P$ value & & & \multicolumn{2}{|c|}{$0.041^{*}$} & \multicolumn{6}{|c|}{0.587} \\
\hline Common & NAF & 9.80 & 3.69 & 4.00 & 17.00 & 7.67 & 2.34 & 4.50 & 12.50 & 0.077 \\
\hline Disfluencies & DAF & 10.70 & 3.41 & 5.50 & 16.00 & 11.17 & 4.47 & 4.50 & 17.50 & 0.633 \\
\hline$P$ value & & & \multicolumn{2}{|c|}{0.513} & \multicolumn{5}{|c|}{$0.006^{*}$} & \\
\hline Speech & NAF & 16.97 & 4.16 & 10.50 & 26.50 & 8.07 & 2.39 & 4.50 & 12.50 & $<0.001^{*}$ \\
\hline discontinuity & DAF & 15.90 & 5.27 & 8.00 & 24.50 & 11.70 & 4.66 & 4.50 & 17.50 & $0.044^{*}$ \\
\hline$P$ value & & & \multicolumn{2}{|c|}{0.712} & \multicolumn{6}{|c|}{$0.008^{*}$} \\
\hline Syllables per & NAF & 186.95 & 35.74 & 127.65 & 240.00 & 233.38 & 34.15 & 179.10 & 292.68 & $0.001^{*}$ \\
\hline minute & DAF & 179.27 & 41.22 & 114.28 & 272.74 & 203.38 & 40.14 & 116.00 & 260.86 & 0.067 \\
\hline$P$ Value & & & \multicolumn{2}{|c|}{0.463} & \multicolumn{6}{|c|}{$0.016^{*}$} \\
\hline Words per & NAF & 104.36 & 19.39 & 77.23 & 142.35 & 125.28 & 22.02 & 91.00 & 164.00 & $0.014^{*}$ \\
\hline minute & DAF & 100.46 & 22.45 & 60.00 & 140.45 & 108.27 & 22.59 & 62.33 & 154.46 & 0.309 \\
\hline$P$ value & & & \multicolumn{2}{|c|}{0.394} & \multicolumn{6}{|c|}{$0.020 *$} \\
\hline
\end{tabular}

* Statistically significant values ( $\mathrm{p}<0.05$ ) - Mann-Whitney test for intergroup comparison and Wilcoxon Signal Test for intragroup comparison between NAF and DAF. Subtitle: $R G$ = research group; $C G=$ control group; $N=$ number of adults; $S D=$ standard deviation, NAF = Non-altered auditory feedback; DAF = Delayed auditory feedback.

minute. RG showed more disfluencies (stuttering-like disfluencies and speech discontinuity) and lower flow of syllables and words per minute in relation to $C G$ (Table 2).

The results regarding the reading are presented in Table 3. The RG intragroup comparison did not show statistically significant difference between NAF and DAF conditions for the different variables analyzed. Fluent adults (CG) showed statistically significant differences for all variables, i.e. stuttering, common disfluencies, speech discontinuity, flow of syllables and words per minute between NAF and DAF conditions. There was an increase in the occurrence of stuttering-like disfluencies and speech discontinuity, as well as a decrease in the amount of common disfluencies in the delayed auditory feedback condition. Regarding the speech rate, CG presented a reduction in the flow of syllables and words per minute in DAF in relation to NAF (Table 3).

The comparison between $R G$ and $C G$ in reading showed that in both NAF and DAF conditions there were statistically significant differences for all variables, namely stuttering-like disfluencies, common disfluencies, speech discontinuity, flow of syllables and words per minute. RG presented more disfluencies (stuttering-like disfluencies, common disfluencies and speech discontinuity) and lower flow of syllables and words per minute compared to $C G$ in both conditions, NAF and DAF (Table 3). 
Table 3. Intragroup and intergroup comparisons regarding the occurrence of stuttering-like disfluencies. common disfluencies. speech discontinuity. flow of syllables and words per minute. in the conditions of non-altered and delayed auditory feedback in reading

\begin{tabular}{|c|c|c|c|c|c|c|c|c|c|c|}
\hline \multirow{2}{*}{\multicolumn{2}{|c|}{ Variables }} & \multicolumn{4}{|c|}{$R G(N=15)$} & \multicolumn{4}{|c|}{$C G(N=15)$} & \\
\hline & & Mean & SD & Minimum & Maximum & Mean & SD & Minimum & Maximum & \\
\hline Stuttering-Like & NAF & 3.67 & 4.48 & 0.00 & 16.50 & 0.13 & 0.23 & 0.00 & 0.50 & $<0.001^{*}$ \\
\hline Disfluencies & DAF & 3.30 & 3.68 & 0.00 & 10.00 & 0.53 & 0.55 & 0.00 & 2.00 & $<0.021^{*}$ \\
\hline$P$ value & & & \multicolumn{2}{|c|}{0.788} & \multicolumn{6}{|c|}{$0.013^{*}$} \\
\hline Common & NAF & 6.43 & 4.40 & 0.00 & 13.50 & 3.37 & 1.01 & 0.00 & 3.50 & $<0.001^{*}$ \\
\hline Disfluencies & DAF & 6.33 & 3.73 & 0.50 & 13.00 & 2.83 & 1.69 & 0.00 & 7.00 & $0.004^{*}$ \\
\hline$P$ value & & & \multicolumn{2}{|c|}{0.571} & \multicolumn{6}{|c|}{$0.002^{*}$} \\
\hline Speech & NAF & 10.10 & 6.25 & 1.00 & 19.50 & 1.50 & 1.07 & 0.00 & 3.50 & $<0.001^{*}$ \\
\hline discontinuity & DAF & 9.63 & 6.79 & 1.00 & 20.50 & 3.37 & 1.73 & 0.50 & 8.00 & $0.004^{*}$ \\
\hline$P$ value & & & \multicolumn{2}{|c|}{0.294} & \multicolumn{6}{|c|}{$0.001^{*}$} \\
\hline Syllables per & NAF & 217.72 & 66.40 & 109.09 & 352.94 & 313.97 & 33.53 & 260.86 & 352.94 & $<0.001^{*}$ \\
\hline minute & DAF & 193.62 & 57.57 & 96.00 & 300.00 & 255.67 & 41.81 & 200.00 & 333.33 & $0.004^{*}$ \\
\hline$P$ value & & & \multicolumn{2}{|c|}{0.100} & \multicolumn{6}{|c|}{$0.002^{*}$} \\
\hline \multirow{2}{*}{ Words per minute } & NAF & 102.17 & 28.05 & 57.27 & 164.11 & 142.47 & 15.77 & 116.08 & 168.33 & $<0.001^{*}$ \\
\hline & DAF & 99.95 & 27.87 & 49.92 & 147.00 & 127.72 & 21.05 & 97.00 & 168.33 & $0.008^{*}$ \\
\hline$P$ value & & & \multicolumn{2}{|c|}{0.570} & \multicolumn{6}{|c|}{$0.009 *$} \\
\hline
\end{tabular}

* Statistically significant values $(\mathrm{p}<0.05)$ - Mann-Whitney test for intergroup comparison and Wilcoxon Signal Test for intragroup comparison between NAF and DAF. Subtitle: $R G$ = research group; $C G=$ control group; $N=$ number of adults; $S D=$ standard deviation. $N A F=$ Non-altered auditory feedback; DAF $=$ Delayed auditory feedback.

\section{DISCUSSION}

The relevance of studies about the influence of temporal auditory cues on speech fluency in stutterers has been emphasized in the literature ${ }^{26,28-30}$. Differences in the nervous system areas related to the auditorymotor circuit were found in persons with stuttering, and these differences may impair the speech fluency planning and execution ${ }^{12,15}$. Thus, this study analyzed the effect of delayed auditory feedback in adults with stuttering in the frequency of disfluencies and speech rate in spontaneous speech and reading of text, and compared it with fluent adults, through a specific software.

The data obtained in the spontaneous speech allowed to verify in the intragroup analysis that the adults with stuttering reduced the amount of stutteringlike disfluencies. Therefore, the delay in auditory feedback caused promotion of the speech fluency of adults with stuttering, as described previously 26,28-30.

The effect of DAF was satisfactory in adults with stuttering because it showed a decrease in the main manifestation of the disorder that is the stutteringlike disfluencies ${ }^{35}$. It is suggested that this delay in the auditory temporal cues can cause adaptations in the nervous system of the person who stutters, thus compensating possible intermittent failures of the nervous system, as described in the literature ${ }^{36}$, in the adequate command of the signals to the motor activity control necessary to the production of fluent speech.

Researches ${ }^{37}$ also suggest that the act of monitoring another speech, as with the chorus effect that delayed auditory feedback causes, assists the stuttering speaker to generate temporal patterns and articulatory gestures that are necessary in fluent speech. The authors believe that DAF can improve sensorimotor multimodal integration, particularly in the neural system related to speech and auditory system processing.

There was a mean reduction in the frequency of stuttering-like disfluencies of $27.5 \%$ with delayed auditory feedback, lower than those reported in other studies that were performed using SpeechEasy $45 \%^{29}$ and $40 \%{ }^{30}$. The difference between these values can be attributed to some variables, as, two studies analyzed used the SpeechEasy to provoke the delay, and besides the delay was used the frequency altered feedback. Another important variable is that Ritto's studies $^{29,30}$ performed a personalized regulation for each participant who chose the most comfortable option of delayed and frequency altered auditory feedback.

Regarding the speech rate of stutters adults' spontaneous speech, the delay in auditory feedback had not 
significant effect on flows of syllables and words per minute. It is worth mentioning that the findings were similar to a study that showed both the statistically significant effect on the reduction in the frequency of stuttering, and also there was no significant effect on the speech rate with $\mathrm{DAF}^{37-39}$. Therefore, the data suggest that the reduction of stuttering with the effect of DAF is not directly related to the reduction of the speech rate.

In the comparative analysis between spontaneous speech and reading of the effect of DAF on adults with stuttering the results showed a positive and significant effect only for stuttering-like disfluencies in spontaneous speech. The data suggest a tendency to decrease the analyzed variables, except for common disfluencies in spontaneous speech, in which there was an increase.

The results regarding the effects of delayed auditory feedback on spontaneous speech and reading of fluent adults showed that there was a significant effect for all measures assessed on the frequency of disfluencies and the speech rate, except for stuttering-like disfluencies in spontaneous speech.

In relation to the increase of the disfluencies caused by the delay in the auditory feedback of fluent adults in the spontaneous speech found in this investigation, the data corroborate reports that described difficulties in the fluent speech with $\mathrm{DAF}^{17,22,29}$. One possible explanation for this finding is that delayed auditory feedback causes in the fluent speakers the adoption of motor control strategies based on auditory feedback, but it results in an interference in a speech monitoring system already effective, and for this reason, increases stuttering-like disfluencies ${ }^{29}$.

According the literature, the most cited effect of delayed auditory feedback in fluent persons is the reduction of speech rate ${ }^{23-25}$. It should be noted that the findings of this study confirm this statement, since in both spontaneous speech and reading there was a decrease in the flow of syllables and words per minute in fluent adults.

The speech rate showed a tendency to decrease under the effect of delayed auditory feedback in both groups, both for spontaneous speech and for reading. However, in relation to the frequency of disfluencies, the adults' behavior with and without stuttering was different, because the RG showed a tendency to decrease disfluencies (except for common disfluencies in spontaneous speech) and the CG a tendency to increase disfluencies (with exception for common disfluencies in reading). This finding suggests that the decrease of speech rate does not necessarily increase the fluency for different speakers.

In the intergroup comparison of spontaneous speech, it was observed that the delay in auditory feedback decreases the differences between adults with and without stuttering for the analyzed variables, because there were more statistically significant differences for NAF in relation to DAF. This result was already expected, since the main characteristic of stuttering is the increase in the amount of stuttering-like disfluencies ${ }^{35}$. Adults with stuttering showed significantly more stuttering-like disfluencies in both NAF and DAF compared to fluent adults, which possibly also led to an increase in speech discontinuity in adults with stuttering, thus showing statistically significant differences between groups in both listening conditions.

It is also known that, due to the increase of the disfluencies in the flow of stutterers' speech, in general occurs a decrease in the flow of syllables and words per minute ${ }^{5}$. The findings of this study corroborate this description as adults with stuttering showed flows of syllable and words per minute significantly lower than the fluent adults in the non-altered auditory feedback condition.

In summary, these findings contributed to characterize the effect of delayed auditory feedback on spontaneous speech and reading of adults with and without stuttering, and to reinforce the positive effect of delay in reducing the frequency of stuttering-like disfluencies in spontaneous speech in adults with stuttering. Further researches may investigate the variability of delayed auditory feedback results specifically in the different severities of stuttering.

\section{CONCLUSION}

The results showed that the delayed auditory feedback promoted fluency in the spontaneous speech of adults with stuttering, without interfering in the speech rate. However, in adults without stuttering, there was an increase in the number of common disfluencies and speech discontinuity in spontaneous speech and reduction of speech rate.

It is worth mentioning that the results of this investigation concern the immediate effect of delay in delayed auditory feedback in adults with stuttering. Researches that analyze the effect of delayed auditory feedback in the long term as well as in other age groups are necessaries. 


\section{REFERENCES}

1. Oliveira CMC, Bohnen AJ. Diagnóstico diferencial dos distúrbios da fluência. In: Lamônica DAC, Britto DBO (ed). Tratado de linguagem: perspectivas contemporâneas. Ribeirão Preto (SP): Booktoy, 2017.p.175-82.

2. Merlo S. Hesitações na fala semi-espontânea: análise por séries temporais. [Dissertação] Campinas(SP): IEL-Universidade de Campinas; 2006.

3. Bohnen AJ. Estudo das palabras gaguejadas por crianças e adultos: caracterizando a gagueira como um disturbio da linguagem. [Tese]. Porto Alegre (RS): Universidade Federal do Rio Grande Sul; 2009.

4. Sasisekaran J. Nonword repetition and nonword reading abilities in adults who do and do not stutter. J Fluency Disord. 2013;38(3):275-89.

5. Arcuri CF, Osborn E, Schiefer AM, Chiari BM. Speech rate according to stuttering severity. Pró Fono R. Atual. Cient. 2009;21(1):45-50.

6. Alm PA. Stuttering and the basal ganglia circuits: a critical review of possible relations. J Commun Disord. 2004;37:325-69.

7. Liu J, Wang Z, Huo Y, Davidson SM, Klahr K, Herder $\mathrm{CL}$ et al. A Functional imaging study of self-regulatory capacities in persons who stutter. PLoS One. 2014;9(2):898-91.

8. Juste FS, Ritto AP, Silva KGN, Andrade CRF. Sequential diadochokinesus in fluent and stuttering children: rate of production and type of errors. Audiol Commun Res. 2016;21e:1-7.

9. Andrade CRF, Juste, FS, Fortunato-Tavares TL. Lexical priming in fluent and with developmental stuttering children. CoDAS. 2013;25(2):95-105.

10. Celeste LC, Martins-Reis VO. The impact of a dysfluency environment on the temporal organization of consonants in stuttering. Audiol Commun Res. 2015;20(1):10-7.

11. Vanhoutte $S$, Cosyns $M$, Van Mierlo $P$, Batens $K$, Corthals $P$, De Letter $M$ et al. When will a stuttering moment occur? The determining role of speech motor preparation. Neuropsy. 2016;86:93-102.

12. Joos K, Ridder D, Boey RA, Vannester S. Functional connectivity changes in adults with developmental stuttering: A preliminar study using quantitative electro-encephalography. Front Hum Neurosci. 2014;8(783):1-9.

13. Cai S, Beal DS, Ghoss SS, Guenther FH, Perkell JS. Impaired timing adjustments in response to time-varying auditory perturbation during connected speech production in persons who stutter. Brain Lang. 2014;129:24-9.

14. Daliri A, Wieland EA, Cai S, Guenther FH, Chang SE. Auditory-motor adaptation is reduced in adults who stutter but not in children who stutter. Dev Sci. No prelo 2017.

15. Chang SE. Subtle differences in brain network connectivity in children who stutter. Procedia Soc Behav Sci. 2015;193:285.

16. Lu C, Long Y, Zheng L, Shi G, Liu L, Ding G et al. Relationship between speech production and perception in people who stutter. Front Hum Neurosci. 2016;10:224.

17. Chon H, Kraft SJ, Zhan J, Loucks T, Ambrose NG. Individual variability in delayed auditory feedback effects on speech fluency and rate in normally fluent adults. J Speech Lang Hear Res. 2013;56(2):489-504.

18. Roob MP, Lynn WL, O'Beime A. An exploration of dichotic listening among adults who stutter. Clin Linguist Phon. 2013;27(9):681-93.

19. Jansson-Verkasalo E, Eggers K, Jarvenpaa A, Suominen K, Van den Bergh B, De Nil L et al. Atypical central auditory, speech-sound discrimination in children who stutter as indexed by the mismatch negativity. J Fluency Disord. 2014;41:1-11.

20. Daliri A, Max L. Modulation of auditory processing during speech movement planning is limited in adults who stutter. Brain Lang. 2015;143:59-68.

21. Prestes R, Andrade AN, Santo RBF, Marangoni AT, Schiefer AM, Gil D. Temporal processing and long-latency auditory evoked potential in stutterers. Braz J Otorhinolaryngol. No prelo 2017.

22. Chester J, Baghai-Ravary L, Möttönen R. The effects of delayed auditory and visual feedback on speech production. J Acoust Soc Am. 2015;137(2):873-83.

23. Stuart A, Kalinowski J. The perception of speech naturalness of post-therapeutic and altered auditory feedback speech of adults with mild and severe stuttering. Folia Phoniatr Logopaedica Basel. 2004;56(6):347-57.

24. Saltuklaroglu T, Kalinowski J, Robbins M, Crawcour $\mathrm{S}$, Bowers A. Comparisons of stuttering frequency during and after speech initiation in unaltered feedback, altered auditory feedback and choral speech conditions. Int J Lang Comm Dis. 2009; 44(6):1000-17. 
25. Yamamoto K, Kawabata H. Temporal recalibration in vocalization induced by adaptation of delayed auditory feedback. Plos One. 2011;6(12):1-8.

26. Foundas AL, Mock JR, Corey DM, Golob EJ, Conture EG. The SpeechEasy device in stuttering and nonstuttering adults: Fluency effects while speaking and reading. Brain Lang. 2013;126(2):141-50.

27. Hudock D, Kalinowski J. Stuttering inhibition via altered auditory feedback during scripted telephone conversations. Int J Lang Commun Disord. 2014;49(1):139-47.

28. Carrasco ER, Schiefer AM, Azevedo MF. Effect of the delayed auditory feedback in stuttering. Audiol Commun Res. 2015;20(2):116-22.

29. Ritto AP, Juste FS, Andrade CRF. The effect of the SpeechEasy ${ }^{\circledR}$ device on acoustic and speech motor parameters of adults who stutter. Audiol Commun Res. 2015;20(1):1-9.

30. Ritto AP, Juste FS, Stuart A, Kalinowiski J, Andrade CRF. Randomized Clinical trial: the use of SpeechEasy ${ }^{\circledR}$ in stuttering treatment. Int $\mathrm{J}$ Lang Commun Disord. 2016;51(6):769-74.

31. Andrade CR, Juste FS. Systematic review of delayed auditory feedback effectiveness for stuttering reduction. J Soc Bras Fonoaudiol. 2011;23(2):187-91.

32. Riley G. Stuttering severity instrument for young children (SSI-3) (3rd ed.). Austin, TX: Pro-Ed. 1994.

33. Saraiva RA, Moojen SPM, Munarski R. Avaliação da compreensão leitora de textos expositivos para fonoaudiólogos e psicopedagogos. Casa do Psicólogo, $1^{\circ}$ ed. 2006.

34. Andrade CRF. Fluência. In: Andrade CRF, Béfi-Lopes DM, Fernandes FDM, Wertzner HF, editores. ABFW - Teste de linguagem infantil nas áreas de fonologia, vocabulário, fluência $\mathrm{e}$ pragmática. 2a ed. Barueri (SP): Pró-Fono; 2011. p. 51-81.

35. Civier O, Bullock D, Max L, Guenther FH. Computational modeling of stuttering caused by impairments in a basal ganglia thalamo-cortical circuit involved in syllable selection and initiation. Brain Lang. 2013;126(3):263-78.

36. Smith A, Sadagopan N, Walsh B, Weber-Fox C. Increasing phonological complexity reveals heightened instability in inter-articulatory coordination in adults who stutter. J Fluency Disord. 2010;35(1):1-18.
37. Park J, Logan KJ. The role of temporal speech cues in facilitating the fluency of adults who stutter. $J$ Fluency Disord. 2015;46:41-55.

38. Kalinowski J, Stuart A, Sark S, Armson J. Stuttering amelioration at various auditory feedback delays and speech rates. Europ J Dis Commun. 1996; 31(3):259-69.

39. Unger JP, Gluck CW, Cholewa, J. Immediate effects of AAF devices on the characteristics of stuttering: A Clinical analysis. J Fluency Disord. 2012;37(2):122-34. 